\title{
Kontribusi Pola Asuh Orang Tua terhadap Minat Belajar Siswa Kelas X SMK N 9 Padang
}

\author{
Meisya Sabilla ${ }^{1}$, Linda Fitria ${ }^{2}$, Rini Sefriani ${ }^{3}$ \\ 1,2,3 Fakultas Keguruan Ilmu dan Pendidikan, Universitas Putra Indonesia YPTK Padang \\ meisyasabilla21@gmail.com
}

\begin{abstract}
This article describes the contribution of parenting styles to students' interest in learning. Parenting patterns are all the ways and actions taken by parents in carrying out their responsibilities as parents. While interest in learning is a sense of preference and a sense of attachment to a thing or activity, without anyone touching. This study aims to determine the magnitude of the contribution of parenting patterns to the learning interest of class $\mathrm{X}$ students in the even semester of SMK Negeri 9 Padang in the 2020/2021 academic year. The method used in this study is quantitative with the type of research that is correlational, the population of this study amounted to 420 people who were registered with a sample of 204 people who were registered in class x for the 2020/2021 academic year. The sampling technique used is purposive sampling technique. So that the number of samples obtained is 204 people. The instrument in this study was a Likert scale questionnaire. Data analysis was performed using statistical programs on IBM Statistical 20 computers and Microsoft Excel. Based on the results of data processing, it is obtained that the rcount value is 0.498 with an rtable value of 0.138 because the rcount value is greater than the rtable value $(0.498>0.138)$, it can be concluded that there is a significant correlation with the direction between the contribution of parenting parents to contribute to student learning interest, with the contribution value is $25 \%$, which means that the parenting pattern of parents' interest in learning is in the low category.
\end{abstract}

keywords: Parenting pattern, interest of learning

\begin{abstract}
Abstrak
Artikel ini mendeskripsikan tentang kontribusi pola asuh orang tua terhadap minat belajar siswa. Pola asuh orang tua merupakan segala cara dan tindakan yang dilakukan oleh orang tua dalam menjalankan tanggung jawab sebagai orang tua. Sedangkan minat belajar adalah suatu rasa lebih suka dan rasa keterikatan pada suatu hal atau aktivitas, tanpa ada yang menyentuh. Penelitian ini bertujuan untuk mengetahui besarnya kontribusi pola asuh orang tua terhadap minat belajar siswa kelas X semester genap SMK Negeri 9 Padang Tahun Ajaran 2020/2021. Metode yang digunakan dalam penelitian ini adalah kuantitatif dengan jenis penelitian yaitu korelasional,populasi penelitian ini berjumlah 420 orang yang terdaftar dengan sampel berjumlah 204 orang yang terdaftar pada kelas x tahun ajaran 2020/2021. Teknik sampling yang digunakan adalah teknik purposive sampling. Sehingga diperoleh jumlah sampel yaitu 204 orang. Instrumen pada penelitian ini adalah angket skala likert. Analisis data dilakukan dengan menggunakan program statistik pada komputer IBM Statistical 20 dan Microsoft Excel. Berdasarkan hasil pengolahan data maka diperoleh nilai rhitung yaitu 0,498 dengan nilai rtabel 0,138 karena nilai rhitung lebih besar dari nilai rtabel $(0,498>0,138)$ maka dapat disimpulkan bahwa terdapat korelasi yang signifikan dengan arah antara kontribusi pola asuh orang tua berkontribusi terhadap minat belajar siswa, dengan nilai kontribusi sebesar $25 \%$ yang bermakna bahwa pola asuh orang tua terhadap minat belajar dalam kategori rendah.
\end{abstract}

Kata kunci: Pola asuh orang tua, minat belajar

(C) 2021 Jurnal PTI

\section{Pendahuluan}

Pendidikan memegang peranan yang sangat penting dalam membentuk pribadi seutuhnya dan mandiri yang berakhlak mulia dan baik bagi lingkungan. UU No 1 mengatur tentang upaya mendidik siswa menjadi generasi penerus bangsa. 20 Tahun 2003 Bab 1 Pasal 1 Sistem Pendidikan Nasional menetapkan: Pendidikan 
adalah usaha sadar dan terencana untuk mewujudkan kesalahan dapat berdampak negatif bagi masa depan suasana belajar dan proses pembelajaran agar peserta anak, baik dari segi kognisi, emosi maupun psikomotor didik secara aktif mengembangkan potensi dirinya (perilaku)[6].

untuk memiliki kekuatan spiritual keagamaan Mendidik anak dengan baik dan benar berarti pengendalian diri, kepribadian kecerdasan, akhlakmulia mengembangkan potensi penuh anak secara alami. serta keterampilan yang diperlukan dirinya, Pertumbuhan fisik anak akan dicapai dengan masyarakat, bangsa dan negara[1]. Pernyataan yang pemenuhan kebutuhan fisik, seperti sandang, pangan, termuat dalam UU No. 1. Pendidikan Nasional No. 20 dan papan. Mengupayakan potensi spiritual anak secara Tahun 2003 memungkinkan kami untuk melakukan wajar melalui pengembangan kecerdasan, emosi dan semua kegiatan tersebut, yaitu pengajaran, pengajaran karakter. Jika didukung dengan metode pengasuhan atau pelatihan. Hal ini diharapkan untuk hasil terbaik di yang tepat, upaya tersebut dapat tercapai[7]. SD, SMP dan SMA[2]. Pendidikan yang diperuntukan Memperkenalkan Dalam keluarga, akan ada cinta, bagi peserta didik itu dalam pelaksanaannya yang kedamaian dan keharmonisan antara orang tua dan mengacu tercapainya tujuan pendidikan nasional. anak. Setiap Orang tua menginginkan anaknya menjadi Menurut Undang-undang No. 20 Tahun 2003 tentang anak yang baik, berbakti, sopan dan mempunyai masa Sistem Pendidikan Nasional, Pasal 3, tujuan pendidikan depan yang cerah, karena itu setiap orang tua nasional adalah mengembangkan potensi peserta didik memegang peranan yang sangat penting dalam agar menjadi manusia yang beriman dan bertakwa membimbing anak, mendampingi anak dalam kepada Tuhan Yang Maha Esa, berakhlak mulia, sehat, kehidupan keseharian anak serta menjadi teladan bagi berilmu, cakap, kreatif, mandiri, dan menjadi warga anak-anaknya[8].

negara yang demokratis serta bertanggung jawab[3]. Pola asuh merupakan pola pengasuhan yang berlaku Pendidikan merupakan kegiatan yang dilakukan dengan dalam setiap keluarga, interaksi antara orang tua dan sengaja supaya peserta didik memiliki sikap dan anak selama mengadakan kegiatan pengasuhan[3]. Pola kepribadian yang baik, sehingga penerapan dalam asuh pada diciptakan oleh adanya interaksi antara orang pendidikan diselenggarakan sesuai dengan sistem tua kepada anak dalam hubungan sehari-hari kehidupan pendidikan yang ada. Dalam hal ini yang menjadi yang ada sepanjang waktu, sehingga orang tua akan penentu kualitas pendidikan adalah ketika bagaimana menghasilkan pemikiran sealiran dengan anak-anak[9]. pendidikan itu disampaikan di tingkat sekolah dasar. Pola asuh secara umum dimaknai sebagai cara orangtua Karena itulah pada saat pendidikan dasar memperlakukan anak dalam berbagai hal, baik dalam pengembangan akan potensi siswa harus lebih berkomunikasi, mendisiplin, memonitor, mendorong diperhatikan dan diarahkan dengan baik Pendidikan atau memberi semangat kepada anak[10]. Pendapat keluarga adalah pendidikan alamiah, setelah anak serta pengalaman setiap individu menjadikan perbedaan lahir[4].

penerapan pola asuh orang tua terhadap anak. Diana

Pendidikan mempunyai peranan penting dalam Baumrind dalam buku karangan Santrock (2002) menciptakan kehidupan bangsa yang cerdas, damai, menyebutkan tiga tipe pola asuh: otoriter, terbuka, dan demokratis. Pendidikan yang pertama otoritatif/demokratis, dan permisif[11].

kali dikenal seorang anak adalah dari keluarga. Orang Penerapan pola asuh orang tua yang kurang tepat dapat tua adalah pendidik yang paling utama dengan disebabkan oleh beberapa faktor yaitu: 1) kurangnya memberikan pola pengasuhan yang diterapkan dalam pengetahuan orang tua terhadap pola asuh anak, 2) keluarganya dan orang tua selalu memberikan yang kesibukan orang tua, 3) gaya hidup yang diterapkan di terbaik untuk anaknya. Orang tua memiliki peran keluarga. Oleh karena itu, betapa pentingnya pola asuh penting dan strategis dalam menentukan kearah mana orang tua terhadap anak. Sebaliknya penerapan pola dan kepribadian anak akan dibentuk. Dalam mengasuh asuh orang tua terhadap anak yang tepat, selain dapat anaknya, orang tua memberikan perhatian, aturan, membentuk anak menjadi jiwa yang mandiri dan penuh disiplin, hadiah dan hukuman, serta tanggapan terhadap tanggung jawab, juga dapat mengetahui minat yang keinginan anaknya. Secara langsung anak akan dimiliki oleh buah hatinya[5].

meresapi dan kemudian menjadi kebiasaan bagi anak- Perkembangan minat tergantung pada kesempatan anaknya[5].

belajar yang dimiliki oleh seseorang. Maksudnya disini, Peran orang tua adalah yang terpenting dalam bahwa perkembangan pada minat seseorang sangat membentuk karakter dan peran seorang anak. Banyak tergantung pada lingkungan dan orangorang yang orang tua percaya bahwa memenuhi kebutuhan materi bergaul dengan anak tersebut, sehingga secara langsung dapat menjamin kebahagiaan anak, sehingga mereka akan berpengaruh pula terhadap kematangan tidak mau memahami minat dan kebutuhan anak secara emosionalnya. Ketika siswa melaksanakan tugas yang spiritual. Namun, banyak juga orang tua yang menarik minatnya, maka siswa akan mengalami efek menganggap bahwa semua ini sepenuhnya menjadi positif yang signifikan seperti kesenangan, tanggung jawab guru, sehingga mengabaikan tugas kegembiraan, dan kesukaan, Minat siswa memberikan penting untuk menentukan masa depan anaknya. Untuk sumbangan yang besar terhadap keaktifan siswa dalam mencapai kesuksesan yang diinginkan, orang tua harus belajar, dengan aktifnya siswa ada peluang yang besar mengasuh anak-anaknya dengan baik. Terjadinya untuk berhasilnya siswa dalam belajar. secara umum 
faktor yang mempengaruhi minat siswa itu ada dua, teknik analisis data dengan statistik deskriptif, uji yang pertama dari dalam diri siswa yang dinamakan hipotesis dan korelasi[15].

minat personal (personal interest) yakni terkait dengan tingkat tingginya pengetahuan, nilai, dan emosi positif yang terdapat dalam diri siswa. Kemudian, yang kedua berasal dari luar diri individu seperti motif sosial dan situasi lingkungan[12].

Siswa yang memiliki minat terhadap suatu objek, cenderung memberikan perhatian kepada objek tersebut. Sikap yang berlangsung terus menerus yang menjadikan seseorang perhatian pada objek yang diminati, sehingga membuat seseorang selektif terhadap objek tersebut. Siswa akan memperhatikan dan memilih sesuatu yang disenanginya, jika siswa berminat belajar maka siswa akan memilih belajar dan akan menyenangi pelajaran tersebut[13].

Pandemi covid-19 ini para peserta didik mengalami minat belajar yang rendah dikarenakan jenuh dalam belajarnya, karena daring, pola asuh orang tua yang tidak sesuai. Berdasarkan observasi dan penelitian yang dilakukan siswa SMK N 9 Padang mempunyai masalah minat belajar yang kurang. Karna orang tua yang sibuk dengan pekerjaan. Sehingga, orang tua kurang mengkontrol anak-anaknya dalam hal belajar. Sehimgga orang tua sulit memberi motovasi belajar pada anak. Lingkungan rumah kuarang mendukung mereka hidup di lingkungan yang rata-rata temantemannya yang tidak sekolah juga berpengaruh dalam hal belajar, tidak pernah masuk sekolah, dan orang tua yang membiarkan anaknya bergaul dengan anak yang tidak sekolah[14]. Tujuan dilakukannya penelitian ini agar tujuan penelitian ini adalah untuk mengetahui seberapa besar kontribusi pola asuh orang tua terhadap minat belajar siswa kelas x di SMK N 9 Padang.

\section{Metodologi Penelitian}

Penelitian ini merupakan penelitian kuantitatif jenis korelasi. Penelitian korelasi adalah penelitian yang dilakukan oleh pene-liti untuk mengetahui tingkat hubungan antara dua variabel atau lebih, tanpa melakukan perubahan, tambahan atau manipulasi terhadap data yang memang sudah ada. Penelitian ini bertujuan mengetahui kontribusi antara pola asuh orang tua terhadap minat belajar siswa.Peneliti ingin mengetahui kontribusi variabel $\mathrm{X}$ dan $\mathrm{Y}$. Populasi penelitian ini yaitu siswa kelas x SMK N 9 Padang sejumlah 420 siswa.

Teknik pengambilan sampel menggunakan purposive sampling dengan jumlah 204 siswa. Teknik pengumpulan data yang digunakan yaitu angket. Teknik angket digunakan untuk mengambil data pola asuh orang tua dan minat belajar siswa. Sebelum angket diberikan kepada sampel, angket diuji dahulu dengan uji validitas dan uji re-liabilitas. Setelah diperoleh data pola asuh orang tua minat belajar siswa dilakukan uji prasyarat yaitu uji normalitas, linearitas. Sedangkan

\section{Hasil dan pembahasan}

Penelitian ini melakukan proses analisis dengan data yang didapat sebelumnya. Adapun data tersebut dapat disajikan pada Tabel.1

Tabel 1. Populasi peserta didik

\begin{tabular}{ccc}
\hline No & Kelas & $\begin{array}{c}\text { Jumlah } \\
\text { Peserta Didik }\end{array}$ \\
\hline 1 & X Tata Boga 1 & 36 \\
2 & X Tata Boga 2 & 36 \\
3 & X Tata Boga 3 & 36 \\
4 & X Tata Boga 4 & 36 \\
5 & X Tata Boga 5 & 35 \\
6 & X Tata Boga 6 & 36 \\
7 & X Perhotelan 1 & 34 \\
8 & X Perhotelan 2 & 34 \\
9 & X Perhotelan 3 & 34 \\
10 & X Perhotelan 4 & 34 \\
11 & X Perhotelan 5 & 34 \\
12 & X Perhotelan 6 & 35 \\
\hline
\end{tabular}

Berdasarkan tabel di atas dapat diketahui bahwa populasi siswa kelas x tahun ajaran 2020/2021 adalah 420 siswa dapat disajikan pada Tabel.2.

\begin{tabular}{clc}
\multicolumn{3}{c}{ Tabel 2 .Statistik Deskriptif Pola Asuh Orang Tua } \\
\hline No & \multicolumn{1}{c}{ Statistik } & Angket Pola Asuh Orang Tua \\
\hline 1 & Mean & 77 \\
2 & Median & 72 \\
3 & Mode & 82 \\
4 & Standard & 9 \\
& Sample & 82 \\
6 & Range & 37 \\
7 & Minimum & 48 \\
8 & Maximum & 85 \\
9 & Sum & 14563 \\
\hline
\end{tabular}

Berdasarkan tabel di atas dapat diketahui bahwa mean 77 , median 72, mode 82, standar deviasi 9, sampel varaince 82 ,range 37 , minimum 48 dan maximum 85 dapat disajikan pada Tabel.3.

Tabel 3. Tingkat Pola Asuh Orang Tua Kelas X SMKN 9 Padang

\begin{tabular}{llrrrr}
\hline \multicolumn{6}{c}{ Kategori } \\
\hline & Freque & Perce & Valid & Cumulativ \\
\hline \multirow{4}{*}{ Vali } & Sangat & 10 & 4,9 & 4,9 & 4,9 \\
d & Rendah & 22 & 10,8 & 10,8 & 15,7 \\
& Sedang & 24 & 11,8 & 11,8 & 27,5 \\
& Tinggi & 66 & 32,4 & 32,4 & 59,8 \\
& Sangat & 82 & 40,2 & 40,2 & 100,0 \\
& Total & 204 & 100,0 & 100,0 & \\
\hline
\end{tabular}




\begin{tabular}{lllrrr}
\hline \multicolumn{5}{c}{ ANOVA Table } \\
\hline & & Sum of & Df & \multicolumn{1}{c}{ Mean } \\
\hline \multirow{2}{*}{ mi } & Between & (Combine & 2032.877 & 21 & 96.804 \\
nat & Groups & Linearitv & 172.510 & 1 & 172.510 \\
bel & & Deviation & 1860.367 & 20 & 93.018 \\
\multirow{2}{*}{ ajar } & Within Groups & & 16059.059 & 182 & 88.237 \\
& & & 18091.936 & 203 & \\
\hline
\end{tabular}

\begin{tabular}{lll}
\hline N & 204 & 204 \\
\hline
\end{tabular}

Berdasarkan tabel diatas dapat diketahuinya besarnya nilai koefisien korelasi antara variabel pola asuh orang tua dengan minat belajar adalah 0,496 dengan taraf signifikansi 0.000 dibandingkan dengan probabilitas 0.05 maka $0.000<0.05$. Dengan menggunakan perbandingan $r_{\text {tabel }}$ dan $r_{\text {hitung }}$ pada taraf minat $5 \%$ jika dilihat dengan membandingkan $r_{\text {hitung }}$ dan $r_{\text {tabel }}$ dengan nilai $r_{\text {tabel }}(\mathrm{df}=\mathrm{N}-2, \mathrm{df}=496-2=494)$. Jadi didapatkan $\mathrm{r}_{\text {tabel }}$ pada derajat adalah 0,138 dapat dikatakan $\mathrm{r}_{\text {hitung }} 0,494>$

Berdasarkan tabel di atas dapat diketahui bahwa tingkat $r_{\text {tabel }}$ 0,138, maka dapat disimpulkan bahwa hipotesis pola asuh orang tua yang paling rendah adalah 4,9 diterima, artinya terdapat korelasi yang signifikan persen dapat disajikan pada Tabel.4.

Tabel 4. Statistik Deskriptif Minat belajar

\begin{tabular}{llc}
\hline No & Statistik & $\begin{array}{c}\text { Angket minat } \\
\text { belajar }\end{array}$ \\
\hline 1 & Mean & 66 \\
2 & Median & 68 \\
3 & Mode & 68 \\
4 & Standard Deviation & 9 \\
5 & Sample Variance & 89 \\
6 & Range & 38 \\
7 & Minimum & 42 \\
8 & Maximum & 80 \\
9 & Sum & 1350 \\
\hline
\end{tabular}

Berdasarkan perhitungan statistik pada tabel 12 dapat dilihat bahwa variabel minat belajar memiliki jumlah responden $(\mathrm{N})$ sebanyak 204, mean 66, median 68 , mode 68, standar deviasi 9, variance 89 , range 38 , nilai minimum 42, nilai maximum 80, dan sum 1350 . Berdasarkan hasil uji normalitas diatas, diketahui bahwa nilai signifikansi $0.025>0.05$. Jadi, dapat disimpulkan bahwa nilai residual kedua variabel berdistribusi normal. berdasarkan hasil uji linearitas antara pola asuh orang tua dengan minat belajar, diketahui bahwa nilai signifikansi deviation from linearity $0.402>0.05$, dapat diartikan terdapat hubungan yang linear antara pola asuh orang tua dengan minat belajar dapat disajikan pada Tabel.5.

\begin{tabular}{|c|c|c|c|}
\hline \multicolumn{4}{|c|}{ Correlations } \\
\hline & & $\begin{array}{l}\text { pola asuh } \\
\text { orang tua }\end{array}$ & $\begin{array}{l}\text { minat } \\
\text { belajar }\end{array}$ \\
\hline \multirow{3}{*}{$\begin{array}{l}\text { pola asuh orang } \\
\text { tua }\end{array}$} & $\begin{array}{l}\text { Pearson } \\
\text { Correlation }\end{array}$ & 1 & ,496 \\
\hline & Sig. (2-tailed) & & , 000 \\
\hline & $\mathrm{N}$ & 204 & 204 \\
\hline \multirow{2}{*}{ minat belajar } & $\begin{array}{l}\text { Pearson } \\
\text { Correlation }\end{array}$ & ,496 & 1 \\
\hline & Sig. (2-tailed) & ,000 & \\
\hline
\end{tabular}

antara pola asuh orang tua dan minat belajar siswa SMKN 9 Padang dapat disajikan pada Tabel.6

\begin{tabular}{cl}
\multicolumn{2}{c}{ Tabel. 6 klasifikasi Kriteria Kontribusi } \\
\hline Persentase kontribusi & Tingkat kontribusi \\
\hline $010 \%$ & Sangat Rendah \\
$10,01 \%-20 \%$ & Rendah \\
$20,1 \%-30 \%$ & Sedang \\
$30,01 \%-40 \%$ & Tinggi \\
$>50 \%$ & Sangat Tnggi \\
\hline
\end{tabular}

\section{Kesimpulan}

Berdasarkan hasil penelitian ini maka dapat disimpulkan terdapat kontribusi pola asuh orang tua terhadap minat belajar siswa kelas X SMK Negeri 9 Padang, pada kategori tinggi, sebesar 24,60 $=25 \%$.

\section{Ucapan terimakasih}

Peneliti mengucapkan terimakasih ke-pada pihak-pihak yang telah membantu dan mendukung dalam penyelesaian manuskrip ini. Semoga dapat bermanfaat bagi peneliti dan pembaca pada umumnya

\section{Daftar Rujukan}

[1] A. Khairunnisa and N. Kurniatin, "Hubungan Pola Asuh Orang Tua Dengan Minat Belajar Remaja Pada Kejar Paket B Di Pkbm Mutiara Bangsa Kecamatan Dramaga Kabupaten Bogor," J. Teknol. Pendidik., vol. 5, no. 1, pp. 155-168, 2016, doi: 10.32832/tek.pend.v5i1.492.

[2] S. N. A. Ika Widhiasih, "Pengaruh Pola Asuh Orang Tua Terhadap Hasil Belajar Ips," J. Kreat. J. Kependidikan Dasar, vol. 7, no. 2, 2017.

[3] M. Murtafiah, "Pengaruh Kecerdasan Emosional, Pola Asuh Orangtua, dan Minat Belajar terhadap Prestasi Belajar Matematika Siswa kelas XI IPA SMA Negeri di Kota Parepare," Saintifik, vol. 2, no. 2, pp. 86-100, 2016, doi: 10.31605/saintifik.v2i2.100.

[4] E. Fatmawati, E. A. Ismaya, and D. Setiawan, "Pola Asuh Orang Tua dalam Memotivasi Belajar Anak pada Pembelajaran Daring," J. Educ., vol. 7, no. 1, pp. 104-110, 2021, doi: 10.31949/educatio.v7i1.871.

[5] A. Fauziah, A. Rosnaningsih, and S. Azhar, "Hubungan Antara Motivasi Belajar Dengan Minat Belajar Siswa Kelas Iv Sdn Poris Gaga 05 Kota Tangerang," J. JPSD (Jurnal Pendidik. Sekol. Dasar), vol. 4, no. 1, p. 47, 2017, doi: 10.26555/jpsd.v4i1.a9594.

[6] K. D. Viandari and K. P. A. Susilawati, "Peran pola asuh orangtua dan penggunaan gadget terhadap interaksi sosial anak

Jurnal PTI (Jurnal Pendidikan Teknologi Informasi) Vol . 8 No. 2 (2021) 1-6 
prasekolah," J. Psikol. Udayana, vol. 6, no. 01, p. 76, 2019, [12] D. Dasmo, N. Nurhayati, and G. Marhento, "Pengaruh Tingkat doi: 10.24843/jpu.2019.v06.i01.p08.

[7] Y. Mulyawati and C. Christine, "Pengaruh Pola Asuh Orang Tua Terhadap Kemandirian Belajar Siswa," JPPGuseda | J. Pendidik. Pengajaran Guru Sekol. Dasar, vol. 2, no. 1, pp. 21- [1 25, 2019, doi: 10.33751/jppguseda.v2i1.990.

[8] N. Kholifah, Supriyadi, and Suwarjo, "Hubungan Persepsi Peserta Didik tentang Pola Asuh Orang Tua, Kebiasaan Belajar dengan Hasil Belajar," JIIP J. Inov. Ilmu Pendidik., vol. 1, no. 1, pp. 83-98, 2019.

[9] S. Faid, A., Aprianto, N., "PRESTASI BELAJAR SISWA Skripsi," vol. 1, no. 3, pp. 19-22, 2010

[10] Y. Amalia Safitri, S. Baedowi, and E. Sari Setianingsih, "Pola Asuh Orang Tua di Era Digital Berpengaruh Dalam Membentuk Karakter Kedisiplinan Belajar Siswa Kelas IV,' Mimb. PGSD Undiksha, vol. 8, no. 3, pp. 508-514, 2020.

[11] N. Sdn, D. I. Kecamatan, and B. Barat, "TERHADAP HASIL BELAJAR SISWA SEKOLAH DASAR." Pendidikan dan Pola Asuh Orangtua Terhadap Prestasi Belajar IPA," Form. J. Ilm. Pendidik. MIPA, vol. 2, no. 2, pp. $132-$ 139, 2015, doi: 10.30998/formatif.v2i2.94.

13] A. S. Nur and B. Massang, "Pengaruh Pola Asuh Orang Tua, Konsep Diri, Dan Motivasi Berprestasi Terhadap Prestasi Belajar Matematika Siswa Kelas Ix Smp Negeri Di Kota Merauke," Suska J. Math. Educ., vol. 2, no. 2, p. 89, 2016, doi: 10.24014/sjme.v2i2.2067.

[14] N. A. Rohmaniyah, K. Khamdun, and E. Widianto, "Analisis Pola Asuh Orang Tua pada Motivasi Belajar Siswa Kelas III SD Negeri 1 Pelemkerep," EduBasic J. J. Pendidik. Dasar, vol. 2, no. 2, pp. 117-124, 2020, doi: 10.17509/ebj.v2i2.27170.

[15] S. Budikuncoroningsih, "Pengaruh Teman Sebaya dan Persepsi Pola Asuh Orang Tua Terhadap Agresivitas Siswa di Sekolah Dasar Gugus Sugarda," JSSH (Jurnal Sains Sos. dan Humaniora), vol. 1, no. 2, p. 85, 2017, doi: 10.30595/jssh.v1i2.1704. 